\title{
Functional significance of regulatory map and structural Amy variants in Drosophila melanogaster
}

\author{
A. J. Klarenberg, \\ K. Sikkema and \\ W. Scharloo
}

Department of Population and Evolutionary Biology, University of Utrecht, Padualaan 8, 3584 CH Utrecht, The Netherlands.

\begin{abstract}
It was shown earlier that variants for the regulatory and structural components of the $\alpha$-amylase gene-enzyme system in populations of $D$. melanogaster show moderate to strong linkage disequilibria suggesting selection. Here we demonstrate directly, that there are selective differences between particular combinations of regulatory variants of map genes, controlling $\alpha$-amylase midgut activity patterns, and structural variants of $\alpha$-amylase encoded by the $A m y$ genes. Adult survival of stocks homozygous for different combinations of Amy and map variants was measured on carbohydrate solutions of starch, maltose and glucose, respectively. On starch, within $A m y^{1}$ and $A m y^{4,6}$ stocks, the map variant with extended $\alpha$-amylase midgut activity pattern lived longer than the map variant with the small $\alpha$-amylase midgut activity pattern. However, both $A m y^{4,6}$ stocks lived longer on starch than the $A m y^{1}$ stocks. On maltose and glucose no differences were recorded. Differences in survival on starch could be related to $\alpha$-amylase activity levels. It is concluded that polymorphism of both the regulatory map genes and the structural Amy genes are important for determination of the selective differences between $D$. melanogaster stocks on starch.
\end{abstract}

\section{INTRODUCTION}

Variants of regulatory genes are characterised as differential effects in tissue-specific, developmental and quantitative expression of enzymes encoded by structural genes. Regulatory variation is caused by separate trans-acting regulatory genes and by cis-acting regulatory elements tightly linked to the structural genes. Regulatory gene variants have been found in several gene-enzyme systems of higher organisms. However, evidence on variation of regulatory genes in populations is very limited (Paigen, 1979; Whitt, 1983; Laurie-Ahlberg, 1985). Increasing knowledge of gene-regulation in higher organisms suggests that genetic variation in regulatory genes has played a crucial role in evolution. For an evaluation of the significance of regulatory variation for evolution it is necessary to measure the adaptive value of regulatory variants that are actually found in populations of a species (MacIntyre, 1982).

The $\alpha$-amylase gene-enzyme system of $D$. melanogaster appears to be well suited in testing the functional significance of regulatory and structural gene variation. It is one of the few geneenzyme systems for which naturally occurring variation of both types has been found in natural populations and selection has been demonstrated. By manipulating substrate (starch) and product (maltose) levels in the diet, selective differences were shown between $\alpha$-amylase variants with high and low activity, $A m y^{4,6}$ and $A m y^{1}$ respectively (de Jong and Scharloo, 1976; Hoorn and Scharloo, 1981). Regulatory differences between $A m y^{1}$ and $A m y^{4,6}$ stocks were found in their developmental profiles of $\alpha$-amylase activity and their reaction to different carbohydrates (Hoorn and Scharloo, 1980 and 1981). Genetic analysis of tissue-specific expression of $\alpha$-amylase in adult and larval midguts (Abraham and Doane, 1978; Klarenberg and Scharloo, 1984; Klarenberg, 1986) showed that both tightly linked cis-acting regulatory elements and a distant trans-acting regulatory gene (mapPMG, 2-79.0) affect the tissue-specific expression of structural $A m y$ variants. In strains homozygous for the second chromosome with two Amy variants, as in $A m y^{4,6}$, the structural $A m y$ gene represents a gene duplication (Amy, 2-77.8; Bahn, 1967; Klarenberg, 1986). The two Amy genes occur as inverted repeats of about $1.6 \mathrm{~Kb}$ long, and are separated by approximately 5 to $6 \mathrm{~Kb}$ DNA. The proximal gene, lies closer to the centromere than the distal gene (Levy, Gemmill and Doane, 1985). Those strains that express only a single $\alpha$-amylase 
isozyme (e.g., $A m y^{1}$ ) contain duplicate copies of the sequences encoding the enzyme. However it was not known whether one or the other, or both copies are functional in strains expressing a single $\alpha$-amylase variant (Gemmill, Schwartz and Doane, 1986). Our results on intragenic recombination between $A m y^{1}$ and $A m y^{4,6}$ are in favour for a non-functional distal $A m y$ gene copy associated with a functional proximal $A m y$ gene in the $A m y^{1}$ and $A m y^{4}$ strains, we investigated (Klarenberg $e t$ al., 1986). Independent regulation was found for other carbohydrate digestion enzymes (Klarenberg and Scharloo, 1982; Klarenberg, 1986) which suggests a large potential for evolution in regulatory systems.

Because differences in $\alpha$-amylase activity may not only be a consequence of differences between the structural Amy genes, but may depend on the properties of tightly linked regulatory genes and elements, it was suggested that regulatory variation could be involved in determining selective differences between the high activity $A m y^{4,6}$ and the low activity $A m y^{1}$ variants (Hoorn and Scharloo, 1979; Scharloo and de Jong, 1980). Evidence for selection on $A m y$ and map (midgut activity pattern) variants was found in their frequencies in populations of different geographic origin which show linkage disequilibria in the same direction and magnitude (Klarenberg and Scharloo, 1986). The $A m y^{4,6}$ variants were more frequently associated with an extensive distribution pattern of $\alpha$-amylase production in both anterior and posterior midgut regions (AMG and PMG), while the $A m y^{1}$ variants had more often a less extensive distribution of $\alpha$-amylase in these midgut regions.

In this paper we present results of a direct test for selection on regulatory map variants in adults of $D$. melanogaster. In addition we show that these differences are associated with differences in total $\alpha$-amylase activity.

\section{MATERIALS AND METHODS}

\section{Fly stocks}

All stocks originated from wild type populations of $D$. melanogaster held in cages for 10-20 years, and were isolated in previous experiments (Klarenberg, 1986). The stocks were isogenic for their second chromosomes, and were therefore homozygous for both $A m y$ (2-77.8) and map (2$79 \cdot 0)$. Four different stocks with the following combinations of $A m y$ and map variants in adults were used: $A m y^{1}$ with map-AMG 100, map-PMG 00;
$A m y^{1}$ with map-AMG 123, map-PMG 12; $A m y^{4,6}$ with map-AMG 120, map-PMG 00;Amy ${ }^{4,6}$ with map-AMG 123, map-PMG 12. The nomenclature of Doane (1980) was followed in designating the $\alpha$-amylase midgut activity patterns. Fig. 1 shows the different $\alpha$-amylase midgut activity patterns as found in 4-6 day aged adults. All stocks were reared on a standard corn-meal medium (Thörig, Schoone and Scharloo, 1975) at $25^{\circ} \mathrm{C}$ and 60 per cent relative humidity. Axenic adults were obtained from a continuous axenic culture on a modified Sang-C medium with 5 per cent Casein, as was described earlier (Klarenberg, 1986).

\section{Survival experiments}

Experiments with adults were performed in vials $(H=8 \mathrm{~cm} ; \varnothing=2.4 \mathrm{~cm})$ filled with $5 \mathrm{ml}$ of a cottonsoaked carbohydrate solution. Non-sterile survival experiments with $A m y^{1}$ stocks were done with soluble starch (Zulkowsky of Merck) and maltose at concentrations ranging from $0-2 \cdot 0$ per cent $(\mathrm{w} / \mathrm{v})$ in deionized water. All flies aged between $2-5 \mathrm{hr}$ were anaesthetised with cold (ice) for
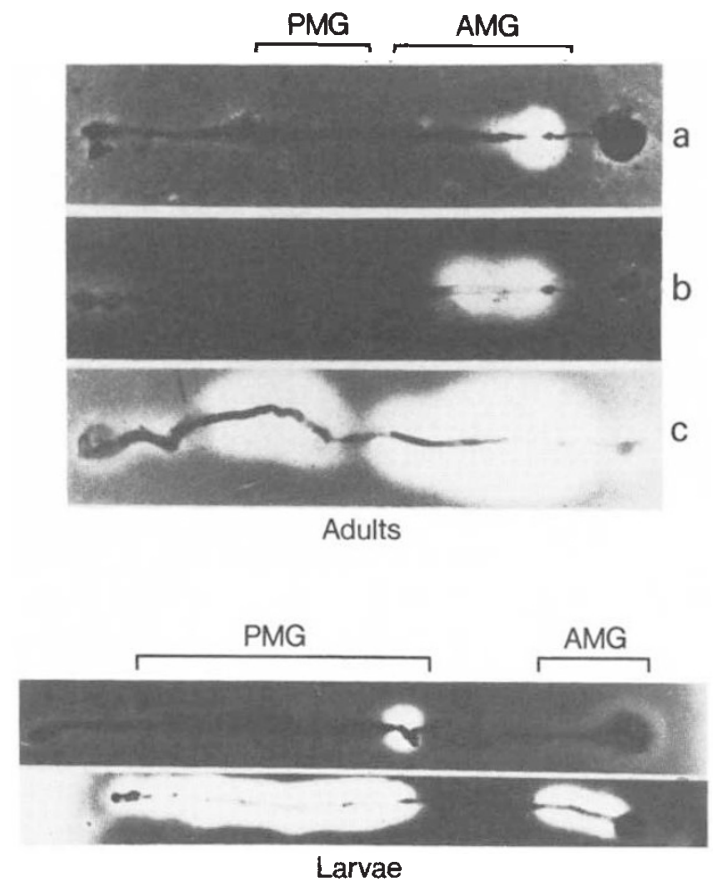

Figure $1 \alpha$-Amylase midgut patterns of the $A m y^{1}$ and $A m y^{4,6}$ stocks used in survival experiments with adults. Adult midgut patterns: a. $A m y^{1}$ map-AMG 100 map-PMG 00, b. $A m y^{4,6}$ map-AMG 120 map-PMG 00, c. $A m y^{1}$ or $A m y^{4,6}$ map-AMG 123 map-PMG 12, and third-instar larvae: d. $A m y^{1}$ map-AMG 0 map-PMG 10, e. $A m y^{4,6}$ map-AMG 1 map-PMG 12. 
10 min. Ten male or ten female flies were put in a vial. For each concentration 10 or 15 replicates were used. Further experimentation with $A m y^{1}$ and $A m y^{4,6}$ stocks was performed under axenic conditions on 2 per cent $(w / v)$ glucose, maltose and starch solutions, to avoid contamination with micro-organisms. Sterile survival experiments were done with $A m y^{1}$ and $A m y^{4,6}$ flies obtained from axenic cultures of these stocks. Vials or cultures that were contaminated with micro-organisms were discarded.

\section{Experiments with larvae}

$A m y^{1}$ and $A m y^{4,6}$ stocks have widely different larval $\alpha$-amylase midgut activity patterns (Klarenberg et al., 1983). In third-instar larvae, $A m y^{1}$ has only $\alpha$-amylase production in a small region of the PMG, while $A m y^{4,6}$ have both AMG and PMG $\alpha$-amylase production, as shown in Figure 1. Cisacting regulatory elements very closely linked to the structural Amy region (less than $0 \cdot 1 \mathrm{cM}$ ) are responsible for these differences in larval $\alpha$ amylase midgut patterns of $A m y^{1}$ and $A m y^{4,6}$ (Klarenberg and Scharloo, 1984). For the measurement of developmental rates from egg to pupa, a total of 50 eggs ( 10 replicates per stock) were put in a vial filled with a medium containing 1.9 per cent agar, 0.4 per cent dead yeast, 0.5 per cent starch and 0.6 per cent nipagin. As a reference in these experiments served an $A m y^{\text {null }}$ stock, which had no detectable $\alpha$-amylase activity (Haj-Ahmad and Hickey, 1982; Klarenberg, 1986).

\section{Enzyme and protein assays}

For determination of $\alpha$-amylase and maltase activities we used respectively the DNSA and Glucostat methods as described by Hoorn and Scharloo (1978). Protein content was assayed with the Biorad protein reagent. All measurements were made as duplicates of two separate homogenates of 25 female adults, aged 4-6 days at a corn-meal food medium. Before homogenization, fresh weight of 25 females of each strain was determined with a Mettler precision balance (ME 22).

\section{RESULTS}

\section{Adult survival}

A first experiment with $A m y^{1}$ was performed under nonsterile conditions. Adults of $A m y^{1}$ stocks with contrasting map variants, namely either a small or an extended $\alpha$-amylase production pattern in the adult midgut (map-AMG 100, map-PMG 00 and map-AMG 123, map-PMG 12) as shown in fig. 1, were subjected to test-solutions with starch or maltose concentrations ranging from $0-2 \cdot 0$ per cent. In both stocks the survival increased with increasing starch or maltose levels. Fig. 2 shows the survival pattern on starch; for maltose similar patterns were obtained (not shown). Because male and female survival was in most instances not different, males and females were pooled. Table 1 gives the survival times to 50 per cent mortality for both $A m y^{1}$ stocks on starch, maltose and water. On $2 \cdot 0$ per cent starch, the $A m y^{\prime}$ adults with the extended $\alpha$-amylase midgut activity pattern lived about 3 days longer than the $A m y^{1}$ adults with the small $\alpha$-amylase midgut activity pattern ( $t$-test, $P<$ $0 \cdot 01)$. On 1.0 per cent starch, this difference was 1.5 days, however not significant $(P>0 \cdot 1)$, as was also found for maltose and water, which served as

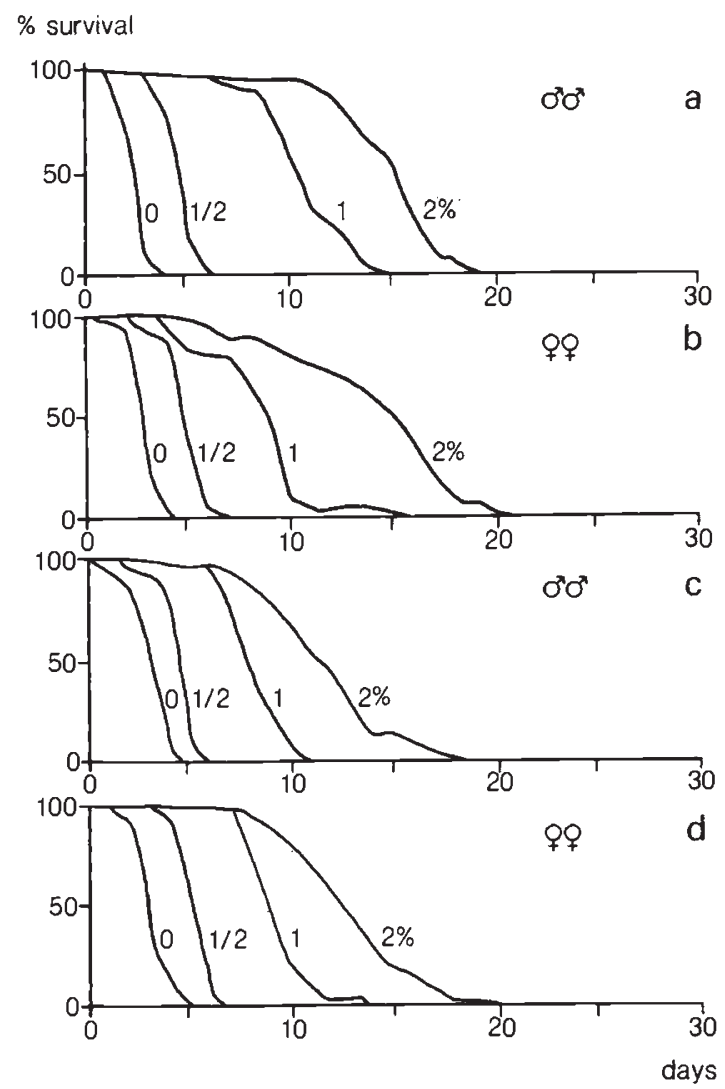

Figure 2 Survival curves of adults with different $\alpha$-amylase midgut patterns on gradients of starch solutions. a. Amy ${ }^{1}$ map-AMG 123 map-PMG 12 males, b. Amy map-AMG 123 map-PMG 12 females, c. Amy' map-AMG 100 mapPMG 00 males, d. Amy ${ }^{1}$ map-AMG 100 map-PMG 00 females. 
Table 1 Survival times to 50 per cent mortality of $A m y^{1}$ adults with different map variants on starch and maltose solutions $(0 \cdot 5-2 \cdot 0$ per cent, $w / v)$ and water ( $\boldsymbol{n}$ is number of vials); survival is expressed in days

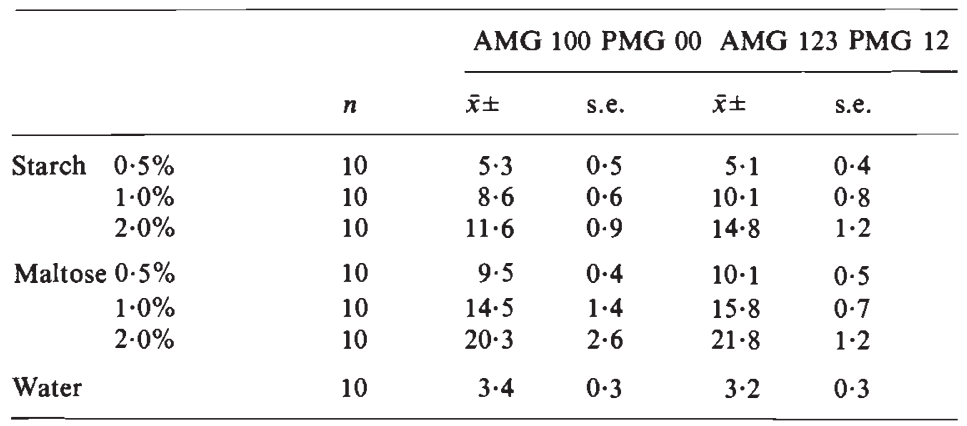

controls (see Hoorn, van Damme and Scharloo, 1979). Under these conditions the flies are doing better on maltose than starch. Although these results demonstrate that differences in survival on starch of $A m y^{1}$ stocks can be attributed to differences in $\alpha$-amylase midgut activity pattern, we found microbial infection of starch and maltose solutions. Therefore we decided to perform the same experiment under sterile conditions.

Survival experiments with axenic flies were done on 2.0 per cent solutions of starch, maltose or glucose. Apart from the $A m y^{1}$ stocks used in the previous experiments, two $A m y^{4,6}$ stocks, one with a small and another with an extended $\alpha$ amylase midgut activity pattern in adults (mapAMG 120, map-PMG 00 and map-AMG 123, mapPMG 12) as shown in fig. 1, were now included in the sterile experiments of which the results are presented in table 2. On starch, the $A m y^{1}$ stock with the extended $\alpha$-amylase midgut activity pattern showed again a higher survival time than the $A m y^{1}$ stock with the small $\alpha$-amylase midgut activity pattern, resulting in a difference of about 5.5 days $(t$-test, $P<0.01)$. Survival under sterile conditions was better than under non-sterile conditions on starch. Comparison of the $A m y^{4,6}$ stocks demonstrates that the stock with the extended $\alpha$ amylase midgut activity pattern also has a longer survival time, the difference, however, was not statistically significant $(P>0 \cdot 1)$. Thus variation is map genes affects survival time of adults. However, it is evident from the data in table 2 , that the survival times of the same $\alpha$-amylase midgut activity pattern variant for the different Amy variants are also different: $A m y^{4,6}$ survival on starch is longer than $A m y^{1}$ survival. The maltose and glucose controls do not show such differences, except that survival on maltose of both $A m y^{1}$ stocks is somewhat lower than the $A m y^{4,6}$ stocks, while on glucose the $A m y^{4,6}$ with the small $\alpha$ amylase midgut activity pattern has a reduced survival compared with the others.

\section{$\alpha$-Amylase and maltase activities}

Table 3 gives the total $\alpha$-amylase and maltase activities of the $A m y^{1}$ and $A m y^{4,6}$ stocks with the small and extended $\alpha$-amylase midgut activity pat-

Table 2 Mean survival times to 50 per cent mortality of $A m y^{1}$ and $A m y^{4.6}$ stocks with different map variants on 2 per cent $(w / v)$ solutions of starch, maltose and glucose under sterile conditions ( $n$ is number of vials)

\begin{tabular}{lcccc}
\hline & \multicolumn{3}{c}{$A m y^{1}$} & \multicolumn{2}{c}{$A m y^{4,6}$} \\
\cline { 2 - 5 } & AMG 100 & AMG 123 & AMG 120 & AMG 123 \\
& PMG 00 & PMG 12 & PMG 00 & PMG 12 \\
\hline Starch $\bar{x}$ & 16.3 & 21.9 & 22.4 & 27.9 \\
$(n=15)$ s.e. & 1.6 & 2.9 & $3 \cdot 3$ & 3.5 \\
Maltose $\bar{x}$ & 17.8 & 18.6 & 20.5 & 21.6 \\
$(n=15)$ s.e. & 3.5 & 2.2 & 2.8 & 3.2 \\
Glucose $\bar{x}$ & 27.0 & 26.0 & 23.6 & 27.6 \\
$(n=15)$ s.e. & 3.0 & 2.9 & 5.1 & 6.0 \\
\hline
\end{tabular}


Table $3 \alpha$-Amylase and maltase activities of 4-6 day aged female fiies. $\alpha$-Amylase is expressed as $\mu \mathrm{g}$ maltose. $\mathrm{min}^{-1} / \mu \mathrm{g}$ fly protein and maltase as $\mu \mathrm{g}$ glucose. $\mathrm{min}^{-1} / \mu \mathrm{g}$ fly protein

\begin{tabular}{llllll}
\hline & \multicolumn{3}{c}{$A m y^{1}$} & \multicolumn{2}{c}{$A m y^{4,6}$} \\
& & AMG 100 & AMG 123 & AMG 120 & AMG 123 \\
& PMG 00 & PMG 12 & PMG 00 & PMG 12 \\
\hline \multirow{2}{*}{$\alpha$-Amylase } & $\bar{x}$ & 1.72 & 2.49 & 3.92 & 4.98 \\
& s.e. & 0.04 & 0.41 & 0.55 & 0.33 \\
\multirow{2}{*}{ Maltase } & $\bar{x}$ & 6.40 & 6.41 & 6.72 & 8.04 \\
& s.e. & 0.30 & 0.93 & 0.13 & 2.01 \\
\hline
\end{tabular}

terns as used in the experiments described above. Total $\alpha$-amylase and maltase activities were measured at an age of 4-6 days, because in this period the developmental profiles of both enzymes reach their maximum and then differences in $\alpha$ amylase activity are most critical for survival (Hoorn and Scharloo, 1980). Table 3 shows that the differences in $\alpha$-amylase activity are in concordance with differences found in survival of these stocks on starch (table 2). For both $A m y^{1}$ and $A m y^{4,6}$, the stock with the extended $\alpha$-amylase midgut activity pattern had a higher $\alpha$-amylase activity, however both $A m y^{4,6}$ stocks had higher $\alpha$-amylase activities in comparison with the $A m y^{1}$ stocks. Maltase activities of all stocks were similar, except the $A m y^{4,6}$ with the most extended $\alpha$ amylase midgut activity pattern, which had a higher activity.

\section{Larval development}

$A m y^{1}$ and $A m y^{4,6}$ stocks have distinct larval $\alpha$ amylase midgut activity patterns. In third-instar larvae, $A m y^{1}$ had only $\alpha$-amylase activity in a small region of the PMG, while $A m y^{4,6}$ had $\alpha$-amylase activity in the AMG and PMG (fig. 1). The Amy ${ }^{\text {null }}$ stock possessed no $\alpha$-amylase at all. In agreement with earlier experiments (Klarenberg, 1986), the $\alpha$-amylase activity of the $A m y^{4,6}$ stock was about four times higher than that of the $A m y^{1}$ stock. Table 4 demonstrates that the developmental time

Table 4 Developmental time of larvae from egg to pupae $(\bar{x} \pm$ s.e. hrs.) of $A m y^{\text {null }}, A m y^{1}$ and $A m y^{4,6}$ stocks. $A m y^{1}$ has only activity in a small region of the PMG, while $A m y^{4,6}$ has both in $A M G$ and PMG $\alpha$-amylase

\begin{tabular}{ll}
\hline & Developmental time \\
\hline$A m y^{\text {null }}$ & $235 \cdot 2 \pm 5 \cdot 8$ \\
$A m y^{1}$ & $220 \cdot 3 \pm 7 \cdot 0$ \\
$A m y^{4,6}$ & $192 \cdot 3 \pm 4 \cdot 3$ \\
\hline
\end{tabular}

from egg to pupa of $A m y^{4,6}$ on the starch medium in $28 \mathrm{hrs}$ shorter than $A m y^{1}$, and $43 \mathrm{hrs}$ shorter than $A m y^{\text {null }}$.

\section{DISCUSSION}

Selection on structural Amy variants in $D$. melanogaster was earlier interpreted as a consequence of a difference in $\alpha$-amylase activity (de Jong and Scharloo, 1976; Hoorn and Scharloo, 1981). It was pointed out that it seemed to be dependent to a large extent on regulatory aspects of gene action on structural differences in enzymes (Hoorn and Scharloo, 1980 and 1981; Scharloo and de Jong, 1980). Here we show that regulatory genes are involved in selection. Therefore linkage disequilibrium results (Klarenberg and Scharloo, 1986) are confirmed. The regulatory genes change the extent of $\alpha$-amylase production in the midgut and total $\alpha$-amylase activity present in the flies. We cannot discriminate between the significance of a wider distribution of $\alpha$-amylase in the midgut and change in total activity. Our results show that it is possible to distinguish between the effects of regulatory adult map variants and structural $A m y$ variants, its tightly linked regulatory elements included, on total $\alpha$-amylase activity and survival of flies on starch. Significant differences were found in adult survival of $A m y^{1}$ stocks with different adult map variants. $A m y^{1}$ flies with the extended $\alpha$-amylase midgut activity pattern survived longer than $A m y^{1}$ flies with a small pattern, which had a lower $\alpha$-amylase activity. $A m y^{4,6}$ showed similar differences. Therefore, regulatory adult map variants have a selective significance.

Moreover, although regulatory aspects are involved in selection on $A m y^{1}$ and $A m y^{4,6}$, we have insufficient understanding of the effects of significant differences in siructural genes causing the electrophoretic differences. First, there is variation in number of $A m y$ genes. $A m y^{4,6}$ has a gene duplication, while $A m y^{1}$ has a single gene (Bahn, 1967; Klarenberg et al., 1986). However, variation in the 
number of $A m y$ genes of the $A m y^{1}$ stocks we used in the experiments presented here cannot be excluded. Analysis of these $A m y^{1}$ stocks at the molecular level could give a final answer (see Levy, Gemmill and Doane, 1985). And secondly, there are kinetic and catalytic differences between $A m y^{1}$ and $A m y^{4,6}$ (in fact $A m y^{4}$ and $A m y^{6}$ ) enzyme variants (Hoorn and Scharloo, 1978; Aben, unpublished). This last aspect deserves further attention with respect to the physiological consequences and their relation to selective difference (see Koehn, Zera and Hall, 1983). This exploration has started successfully for alcohol dehydrogenase in $D$. melanogaster (Heinstra et al., 1983; Bodmer and Ashburner, 1984; Eisses et al., 1985; Moxon et al., 1985; Winberg et al., 1985).

Evidence for selective differences between regulatory variants has been found in $D$. melanogaster for alcohol dehydrogenase (Dickinson et al., 1984) and for phosphoglucomutase in rainbow trout (Allendorf et al., 1983). In D. pseudoobscura, frequencies of both electrophoretic $\alpha$ amylase variants and midgut activity pattern variants changed in cage populations (Powell and Andjelkovic, 1983). However genetic analysis in this species was unsuccessful in localizing map genes (Powell and Lichtenfels, 1979). In $D$. melanogaster it has been established that factors affecting $\alpha$-amylase levels are mainly responsible for fitness differences under conditions when starch is the limiting factor for survival (de Jong and Scharloo, 1976; Hoorn and Scharloo, 1980 and 1981). These factors may include both structural and regulatory properties of the $\alpha$-amylase gene-enzyme system.

This study shows that polymorphisms in regulatory map genes affecting the tissue-specific expression of $\alpha$-amylase in the midgut of adults of $D$. melanogaster have selective significance. In addition, differences in structural parts of $A m y$ genes and their tightly linked regulatory elements are also very important in determining the selective differences of stocks with different Amy variants.

Until recently most studies on enzyme variation were to a large extent limited to electrophoretic variants, i.e., variation in structural genes. To solve questions about the functional significance of enzyme variation, it is necessary to have knowledge of both the regulatory and structural aspects of gene-enzyme systems. The $\alpha$-amylase gene-enzyme system in $D$. melanogaster provides in this respect a large potential for future research and may serve as a model for elucidating the processes and mechanisms involved in regulation of geneexpression.
Acknowledgments We wish to thank Mss B. L. A. de Ruiter for technical assistance. Further we are much indebted to $\mathrm{Mr}$ P. Brouwer and Mr D. Smit for figures and photographs. The investigations were supported by the Foundation for Biological Research (BION), which is subsidized by the Netherlands Organization for the Advancement of Pure Research (Z.W.O.).

\section{REFERENCES}

ABRAHAM, I. AND DOANE, W. W. 1978. Genetic regulation of tissue-specific expression of amylase structural genes in Drosophila melanogaster. Proc. Natl. Acad. Sci. USA, 75, 4446-4450.

ALLENDORF, F. W., KNUDSEN, K. L. AND LEARY, R. F. 1983. Adaptive significance of differences in the tissue-specific expression of a phosphoglucomutase gene in rainbow trout. Proc. Natl. Acad. Sci. USA, 80, 1397-1400.

BAHN, E. 1967. Crossingover in the chromosomal region determining amylase isozymes in Drosophila melanogaster. Hereditas, 58, 1-12.

BODMER, M. AND ASHBURNER, M. 1984. Conservation and change in the DNA sequences coding for alcohol dehydrogenase in sibling species of Drosophila. Nature, 309, 425-430.

DICKINSON, W. J., ROWAN, R. G. AND BRENNAN, M. D. 1984. Regulatory gene evolution: adaptive differences in expression of alcohol dehydrogenase in Drosophila melanogaster and Drosophila simulans. Heredity, 52, 215225.

DOANE, w. W. 1980. Midgut amylase activity patterns in Drosophila: nomenclature. Drosophila Inform. Serv., 55, 36-39.

EISSES, K. TH., SCHOONEN, W. G. E. J., ABEN, W., SCHARLOO, W. AND THÖRIG, G. E. W. 1985. Dual function of the alcohol dehydrogenase of Drosophila melanogaster: ethanol and acetaldehyde oxidation by two allozymes ADH-71K and ADH-F. Mol. Gen. Genet., 199, 76-81.

GEMMILL, R. M., SCHWARTZ, P. E. AND DOANE, W. W. 1986. Structural organization of the Amy locus in seven strains of Drosophila melanogaster. Nucl. Acids. Res., 14, 53375352.

HAJ-AHMAD, Y. AND HICKEY, D. A. 1982. A molecular explanation of frequency-dependent selection in Drosophila. Nature, 299, 350-352.

HEINSTRA, P. W. H., EISSES, K. TH., SCHOONEN, W. G. E. J. ABEN, W., DE WINTER, A. J., VAN DER HORST, D. J., VAN MARREWIJK, W. J. A., BEENAKKERS, A. M. TH., SCHARLOO, W. AND THÖRIG, G. E. W. 1983. A dual function of alcohol dehydrogenase in Drosophila. Genetica, 60, 129137.

HOORN, A. J. W. AND SCHARLOO, W. 1978. The functional significance of amylase polymorphism in Drosophila melanogaster. I. Properties of two amylase variants. Genetica, 49, 173-180.

HOORN, A. J. W., VAN DAMME, J. M. M. AND SCHARLOO, W 1979. The functional significance of amylase polymorphism in Drosophila melanogaster. IV. Starch and maltose as food components. Neth. J. Zool, 29, 1-8.

HOORN, A. J. W. AND SCHARLOO, W. 1979. Selection on enzyme variants in Drosophila. Aquilo Ser. Zool., 20, 41-48.

HOORN, A. J. W. AND SCHARLOO, W. 1980. Functional significance of amylase polymorphism in Drosophila melanogaster. III. Ontogeny of amylase and some $\alpha$ glucosidases. Biochem. Genet., 18, 51-63. 
HOORN, A. J. W. AND SCHARLOO, w. 1981. The functional significance of amylase polymorphism in Drosophila melanogaster. VI. Duration of development and amylase activity in larvae when starch is a limiting factor. Genetica, $55,195-201$.

DE JONG, G. AND SCHARLOO, W. 1976. Environmental determination of selective significance or neutrality of amylase variants in Drosophila melanogaster. Genetics, 84, 77-94.

KLARENBERG, A. J. AND SCHARLOO, w. 1982. Midgut activity pattern variation in alpha-amylase and other carbohydrases in Drosophila melanogaster. Genetics, 100, s36-37.

KLARENBERG, A. J., JACOBS, P. J. M., VERMEULEN, C. AND SCHARLOO, w. 1983. Environmental and genetic control of larval midgut pattern variation of $\alpha$-amylase in Drosophila melanogaster. Genetics, 104, s43.

KLARENBERG, A. J. AND SCHARLOO, w. 1984. Tissue-specific control of Amy variants in Drosophila melanogaster: cisregulation in larvae versus trans-regulation in flies. Genetics, 107, s56.

KLARENBERG, A. J. 1986. Genetic variation in regulation of $\alpha$-amylase expression in Drosophila melanogaster. Ph.D. Thesis. University of Utrecht.

KLARENBERG, A. J. AND SCHARLOO, w. 1986. Non-random association between structural Amy and regulatory map variants in Drosophila melanogaster. Genetics, 114,875-884.

KLARENBERG, A. J., VISSER, A. J. S., WILLEMSE, M. F. M. AND SCHARLOO, w. 1986. Genetic localization and action of regulatory genes and elements for tissue-specific expression of $\alpha$-amylase in Drosophila melanogaster. Genetics, 114 , $1131-1145$.

KoEHn, R. K., ZERA, A. J. AND HALL, J. G. 1983. Enzyme polymorphism and natural selection. Nei, M., and Koehn, R. K. (eds.). In Evolution of Genes and Proteins, Sinauer Assoc. Inc., pp. 115-136.

LAURIE-AHLBERG, C. C. 1985. Genetic variation affecting the expression of enzyme-coding genes in Drosophila: an evolutionary perspective. Rattazzi, M. C., Scandalios, J. G. and Whitt, G. S. (eds.). In Isozymes: Current Topics in Biological and Medical Research, Vol. 12, Alan R. Liss Inc., New York, pp. 33-88.
LEVY, J. N., GEMMILl, R. M. AND DOANE, W. W. 1985. Molecular cloning of $\alpha$-amylase genes from Drosophila melanogaster. II. Clone organization and verification. Genetics, 110, 313-324.

MACINTYRE, R. J. 1982. Regulatory genes and adaptation: past, present and future. Evol. Biol, 15, 247-285.

MOXON, L. N., HOLMES, R. S., PARSONS, P. A., IRVING, M. G. AND DODDRELL, D. M. 1985. Purification and molecular properties of alcohol dehydrogenase from Drosophila melanogaster: evidence from NMR and kinetic studies for function as an aldehyde dehydrogenase. Comp. Biochem. Physiol., 80B, 525-535.

PAIGEN, K. 1979. Acid hydrolases as models of genetic control. Ann. Rev. Genet., 13, 417-466.

POWEll, J. R. AND LICHTEnfels, J. M. 1979. Population genetics of Drosophila amylase. I. Genetic control of tissuespecific expression in D. pseudoobscura. Genetics, 92, 603 612.

POWEll, J. R. AND ANDJElkovic, M. 1983. Population genetics of Drosophila amylase. IV. Selection in laboratory populations maintained on different carbohydrates. Genetics, 103, 675-689.

SCHARLOO, W. AND DE JONG, G. 1980. Selection for amylase allozymes in Drosophila melanogaster: a reply. Evolution, $34,608-610$.

THÖRIG, G. E. W., SCHOONE, A. A. AND SCHARLOO, W. 1975. Variation between electrophoretically identical alleles at the alcohol dehydrogenase locus in Drosophila melanogaster. Biochem. Genet., 13, 721-731.

WHITT, G. S. 1983. Isozymes as probes and participants in developmental and evolutionary genetics. Rattazzi, M. C., Scandalios, J. G. and Whitt, G. S. (eds.). In Isozymes: Current Topics in Biological and Medical Research, Vol. 10, Alan R. Liss Inc., New York, pp. 1-40.

WINBERG, J. O., HOVIK, R. AND MCKINLEY-MCKEE, J. S. 1985. The alcohol dehydrogenase alleloenzymes $A d h^{\mathrm{S}}$ and $A d h^{\mathrm{F}}$ from the fruitfly Drosophila melanogaster: An enzymatic assay to determine the active-site concentration. Biochem. Genet., 23, 205-216. 